\title{
Molecular Characterization of Meloidogyne hispanica (Nematoda, Meloidogynidae) by Phylogenetic Analysis of Genes Within the rDNA in Meloidogyne spp.
}

\author{
Blanca B. Landa, Instituto de Agricultura Sostenible (IAS), Consejo Superior de Investigaciones Científicas \\ (CSIC), Apdo. 4084, 14080 Córdoba, Spain; Juan E. Palomares Rius, IAS-CSIC; Nicola Vovlas, Istituto per la \\ Protezione delle Piante, Sezione di Bari, Consiglio Nazionale delle Ricerche, (C.N.R.), Via G. Amendola 165/A, \\ 70126 Bari, Italy; Regina M. D. G. Carneiro, Embrapa Recursos Genéticos e Biotecnologia, C.P. 02372, 70849- \\ 970, Brasilia, DF, Brazil; Carla M. N. Maleita and Isabel M. de O. Abrantes, Instituto do Mar-CIC, Departamento \\ de Zoologia, Universidade de Coimbra, Coimbra 3004-517, Portugal; and Pablo Castillo, IAS-CSIC
}

\begin{abstract}
Landa, B. B., Palomares Rius, J. E., Vovlas, N., Carneiro, R. M. D. G., Maleita, C. M. N., Abrantes, I. M. de O., and Castillo, P. 2008. Molecular characterization of Meloidogyne hispanica (Nematoda, Meloidogynidae) by phylogenetic analysis of genes within the rDNA in Meloidogyne spp. Plant Dis. 92:1104-1110.

In the past, the distribution of Meloidogyne hispanica, the Seville root-knot nematode, appeared to be restricted to the southern part of Spain and Prunus spp.; however, its distribution has been confirmed to be worldwide because it occurs in all continents (Europe, Africa, Asia, Australia, and North, Central, and South America). Differentiation of M. hispanica from other Meloidogyne spp., mainly $M$. arenaria, can be very difficult using morphological and biological traits data. These species are quite similar and can be regularly confused in inaccurate taxonomic comparisons. In this study, species-specific polymerase chain reaction (PCR) and phylogenetic analysis of sequences from three ribosomal (r)DNA regions (18S, internal transcribed spacer [ITS]1-5.8S-ITS2, and D2-D3 of 28S) were used to characterize three $M$. hispanica isolates from different geographical origins (Brazil, Portugal, and Spain). Molecular analyses showed identical sequences for all three isolates for the three rDNA regions. Maximum parsimony analysis of the three rDNA regions and the species-specific PCR demonstrated and supported the differentiation of $M$. hispanica from $M$. incognita, M. javanica, and M. arenaria and from all described root-knot nematode species.
\end{abstract}

Additional keywords: diagnosis, isozyme phenotypes, morphology

Meloidogyne hispanica, the Seville rootknot nematode, was first found in Seville, southern Spain, infecting rootstocks of peach, Prunus persica (L.) Batsch, in a commercial peach orchard. It was first studied biochemically by Dalmasso and Bergé (11), who found certain enzyme patterns similar to those of $M$. incognita with which, at that time, it was grouped. Later, Triantaphyllou (35) found that the same isolate differed from $M$. incognita isolates in the behavior of its chromosomes during oogenesis. Subsequently, on the basis of additional research on the morphology, cytology, mode of reproduction, and biochemistry, Hirschmann (23) described it as a new species. Since then, the nematode has been reported causing big losses in yield and quality of Prunus spp.

Corresponding author: P. Castillo

E-mail: pcastillo@ias.csic.es

B. B. Landa and J. E. Palomares Rius contributed equally to this work.

Accepted for publication 14 March 2008.

doi:10.1094/PDIS-92-7-1104

(c) 2008 The American Phytopathological Society crops in many countries, particularly under Mediterranean climate conditions $(14,19,30)$.

Originally, $M$. hispanica appeared to be restricted to the southern part of Spain and Prunus spp. but its distribution has been confirmed to be worldwide. $M$. hispanica has been reported on sugar cane (20), grapevine (Vitis sp.), snapdragon (Antirrhinum majus L.), and geranium (Pelargonium notatum (L.) L'Herit) in South Africa (26); fig trees (Ficus carica L. ) and carnation (Dianthus caryophyllum L.) in Portugal (1); grapevine in Australia (24, 31); sugar beet (Beta vulgaris L.) in Spain (25); tomato (Solanum lycopersicum L.) in Burkina Faso and Malawi (36); squash (Cucurbita morchata Duchesse ex. Lam.) and sugar cane (Saccharum officinarum L.) in Brazil (5); and 'Cavendish' bananas (Musa sp.) in Martinique (10). Most of these reports identified $M$. hispanica by its characteristic perineal pattern and esterase phenotype, with three bands which can be clearly differentiated from the esterase phenotypes of $M$. arenaria, $M$. incognita, or $M$. javanica $(5,18,20,28)$.

The differentiation of $M$. hispanica as a distinct species has caused some controversy in the past. Indeed, $M$. hispanica can be very difficult to distinguish from $M$. arenaria using morphological characters even by expert nematologists because both species are quite similar in morphological and biological traits $(6,24)$. In fact, both species could be regularly confused in inaccurate taxonomic comparisons, because the host-range response is similar for both species $(6,23)$. A good example of that situation was found in South Africa where, during several years, the identity of $M$. hispanica was erroneously associated with $M$. arenaria thamesi (26).

Molecular approaches useful for distinguishing Meloidogyne spp. include random amplified polymorphic DNA (RAPD; 3), restriction fragment length polymorphisms (RFLP; 24), and sequence differences within ribosomal DNA (rDNA; $2,9,38$ ) or mitochondrial DNA (mtDNA; 4). In addition, development of species-specific sequence-characterized amplified region (SCAR) primers has been achieved for rapid identification of the three most widely distributed species, $M$. arenaria, $M$. incognita, and M. javanica (39). M. hispanica has been differentiated from the four major species of Meloidogyne (M. arenaria, $M$. hapla, $M$. incognita, and $M$. javanica) by RFLPs of mtDNA genes $(8,31)$. The mitotically parthenogenetic root-knot nematodes $M$. arenaria, $M$. incognita, and $M$. javanica have relatively little sequence variation in their internal transcribed spacer (ITS) regions for species differentiation (2). In fact, De Ley et al. (13) studied ITS1, 5.8S, and ITS2 rDNA sequences from several Meloidogyne spp., including $M$. hispanica, and verified that a group of species $(M$. hispanica, $M$. incognita, $M$. javanica, $M$. morocciensis, and both races of $M$. arenaria) have nearly identical ITS region sequences. No additional molecularbased diagnostic analyses have been conducted to support the specific identification of $M$. hispanica. The occurrence of $M$. hispanica outside the Iberian Peninsula points out the relative lack of knowledge concerning the distribution and importance of this root-knot nematode species. This could be related to the difficulty of correct diagnosis of this nematode by using morphological diagnostic approaches or an erroneous identi- 
fication of $M$. hispanica to other closely related Meloidogyne spp.

The objective of this study was to provide molecular-based analysis, including species-specific polymerase chain reaction (PCR) and phylogenetic analysis of sequences from the 18S, ITS1-5.8S-ITS2, and D2-D3 of 28S rDNA to clarify and support the differentiation of $M$. hispanica from the common species $M$. incognita, $M$. javanica, and $M$. arenaria, and from all other Meloidogyne spp. from which molecular sequence data are available.

\section{MATERIALS AND METHODS}

M. hispanica isolates. Three isolates of the Seville root-knot nematode originated from peach rootstocks from the type locality in Seville, Spain (kindly supplied by D. Esmenjaud, INRA, Antibes, France); squash from the state of Bahia, Brazil; and carnation from Portugal were used in this study. All the isolates were maintained separately on tomato in the greenhouse. Nematode inocula for isozyme and molecular analyses were obtained from a single egg mass of each nematode isolate handpicked from infected tomato roots, surface-disinfested with $1 \% \mathrm{NaOCl}$ for 4 min, and washed four times in sterile distilled water. The disinfested egg masses were placed onto roots of 4- to 6 week-old tomato plants, cv. Roma, transplanted into 1-liter clay pots filled with sterile clay loam soil. Pots were placed in a growth chamber at $25 \pm 1{ }^{\circ} \mathrm{C}, 60$ to $90 \%$ relative humidity, and a 14-h photoperiod of fluorescent light at $360 \pm 25 \mu \mathrm{Em}^{-2} \mathrm{~s}^{-1}$. Sixty days after inoculation, plants were removed from the pots, the root systems were washed free of soil, and adult females were extracted from the roots. The morphological studies were based on perineal patterns. Females were placed in a large drop of $45 \%$ lactic acid and the perineal patterns were cut and cleaned (32). Up to 20 patterns of each isolate were then mounted in desiccated glycerin and examined.

Isozyme analysis. Esterase (Est) and malate dehydrogenase (Mdh) phenotypes of $M$. hispanica isolates were compared with a reference isolate of $M$. javanica from potato (37). Five young, egg-laying females of each isolate were macerated in microtubes containing $5 \mu \mathrm{l}$ of $20 \%$ (wt/vol) sucrose, $1 \%$ (vol/vol) Triton $\mathrm{X}-100$, and $0.01 \%$ (wt/vol) bromophenol blue dye. Electrophoresis was carried out in 7-by-8$\mathrm{cm}, 0.75-\mathrm{mm}$ thick, separating $(\mathrm{pH} 8.8)$ and stacking ( $\mathrm{pH}$ 6.8) homogeneous gels, 7 and $4 \%$ polyacrylamide, respectively, with Tris-glycine buffer in a Mini Protean II electrophoresis unit (BioRad Laboratories). Gels were stained for Est with the substrate $\alpha$-naphthyl acetate, and Fast Blue RR (Sigma-Aldrich, Madrid) for Mdh (17).

DNA extraction, PCR, and sequencing. Total genomic DNA was extracted from at least five to eight single adult females per sample according to Castillo et al. (7). PCR assays were carried out using the SCAR primers Far/Rar (M. arenaria), Finc/Rinc (M. incognita), and $\mathrm{Fj} / \mathrm{Rj}(M$. javanica) and reaction conditions as described by Zijlstra et al. (39). Amplifications were performed with a PTC 200 thermocycler (MJ Research, Watertown, MA). The different regions of rDNA were amplified as described by Castillo et al. (7) and Tigano et al. (34) using the following primer sets: $5367\left(5^{\prime}\right.$-TTGATTACGTCC CTGCCCTTT-3') and F195 (5'-TCCTCC GCTAAATGATATG- $3^{\prime}$ ) for the ITS region, MelF (5'-TACGGACTGAGATAA TGGT-3') and MelR (5'-GGTTCAAGC CACTGCGA-3') for the $18 \mathrm{~S}$, and D2A (5'ACAAGTACCGTGAGGGAAAGTTG-3') and D3B (5'-TCGGAAGGAACCAGC TACTA-3') for the D2-D3 region of 28S.

SCAR amplification products were separated using the FlashGel system (Cambrex Bio Science Rockland, Inc., Rockland, ME) by electrophoresis at 250 $\mathrm{V}$ for 5 to $7 \mathrm{~min}$. The AmpliSize 50- to 2,000-bp ladder (BioRad Laboratories) was used for electrophoresis. Reactions were repeated at least twice and always included negative controls (no DNA) and positive-control DNA from $M$. arenaria (6) and $M$. incognita (27) adult females from olive nurseries and $M$. javanica adult females from potato (37).

The ITS1-5.8S-ITS2, 18S, and the D2D3 of $28 \mathrm{~S}$ of rDNA products were purified after amplification with a gel extraction kit (Geneclean turbo; Q-BIOgene S.A., France), quantified using the Quant-iT DNA Assay Kit Broad Range fluorometric assay (Molecular Probes, Inc.) with a Tecan Safire fluorospectrometer (Tecan Spain, Barcelona, Spain) according to the manufacturer's instructions, and used for direct DNA sequencing. DNA fragments from two PCR amplifications from different females were sequenced in both directions using the same amplification primers with a terminator cycle sequencing readyreaction kit (BigDye; Perkin-Elmer Applied Biosystems, UK) according to the manufacturer's instructions. The resulting products were purified and run on a DNA multicapilar sequencer (Model 3100 genetic analyzer; Applied Biosystems) at the University of Córdoba. All rDNA sequences of $M$. hispanica were deposited in the GenBank as EU443606, EU444607, and EU443608 for the D2-D3 region; EU443609, EU443610, and EU443611 for 18S; and EU443612, EU443613, and EU443614 for ITS1-5.8S-ITS2 for the Spain, Brazil, and Portugal isolates, respectively.

Phylogenetic analysis. The sequences of the other Meloidogyne spp. used for phylogenetic analysis were obtained from GenBank and one sequence of Pratylenchus coffee (15) was used as an outgroup taxa. All of the sequences included in the phylogenetic tree analysis were first aligned by using Bionumerics software (version 4.5; Applied Maths, Kortrijk, Belgium). Phylogenetic trees were generated by the neighbor-joining (NJ) and maximum-parsimony (MP) methods with unweighted pair group with arithmetic means (UPGMA) cluster analysis using Bionumerics 4.5 software. Each phylogram was bootstrapped 1,000 times to assess the degree of support for the phylogenetic branching indicated by the optimal tree for each method.

\section{RESULTS}

Morphology and isozyme analysis. The perineal patterns in all three isolates of $M$. hispanica are oval to rectangular with a low dorsal arch and some with a higher, squarish arch and often widely spaced lateral lines with fringe-like striae (Fig. 1). The isozyme electrophoresis revealed two slow and a medium Est bands coincident with the S2-M1 phenotype (Fig. 2) and a N3 Mdh phenotype with a strong band and two additional weaker bands after prolonged staining (Fig. 2) that did not occur in the Est and Mdh phenotypes of $M$. javanica, which showed J3 and N1 phenotypes, respectively (Fig. 2).

PCR with species-specific primers. Species-specific PCR assays using DNA from $M$. arenaria, $M$. incognita, and $M$. javanica reference isolates gave rise to the expected $M$. incognita, $M$. javanica, and $M$. arenaria amplicons of 1,200, 670, and 420 bp, respectively (39; Fig. 3). No amplification occurred in the $M$. hispanica isolates and in the control (Fig. 3).

Phylogenetic analysis. The topology of the phylogenetic trees obtained with the NJ and MP was consistent with only a few exceptions. Therefore, only MP trees are shown in Figures 4, 5, and 6 with bootstrap values. Different Meloidogyne spp. were used in the phylogenetic analysis of $18 \mathrm{~S}$, ITS1-5.8S-ITS2, and D2-D3 genes due to sequence availability in the GenBank database. Amplification of the ITS-5.8S-ITS2 with primers 5367/F195 yielded a single fragment of approximately 750 bp for $M$. hispanica. The ITS sequences of all three isolates of $M$. hispanica shared $100 \%$ homology, showed highest similarity with that of $M$. mayaguensis, and clearly were different from that of $M$. arenaria, $M$. incognita, M. javanica, M. thailandica, and all other Meloidogyne spp. assayed. The closest sequence-related neighbors of $M$. hispanica isolates were $M$. mayaguensis (93.0 to $96.2 \%), M$. thailandica (93.3 to 93.5\%), M. incognita (90.5 to $90.7 \%$ ), $M$. arenaria (90.0 to $93.4 \%$ ), and $M$. javanica (90.5 to $93.0 \%$ ). Similarity levels of $M$. hispanica toward other Meloidogyne spp. were below $90 \%$. The optimal phylogenetic tree obtained from MP analysis revealed that the three $M$. hispanica isolates formed an independent clade with a high bootstrap support occupying a basal posi- 
tion in a clade with different Meloidogyne spp. such as $M$. mayaguensis, $M$. arenaria, $M$. javanica, $M$. thailandica, and $M$. incognita and as a sister taxon to M. hapla. These Meloidogyne spp. from warm-temperate, tropical, and subtropical regions were more distantly related to other Meloidogyne spp., some of them from cool temperate regions (e.g., M. fallax and M. chitwoodi) that clustered in different clades (Fig. 4).

Amplification of the D2-D3 region of the $28 \mathrm{~S}$ gene with primers $\mathrm{D} 2 \mathrm{~A} / \mathrm{D} 3 \mathrm{~B}$ yielded a single fragment of approximately $750 \mathrm{bp}$ for $M$. hispanica. The D2-D3 sequences of all three isolates of $M$. hispanica shared $100 \%$ homology. The closest sequence-related neighbors of $M$. hispanica species were $M$. konaensis (96.1 to $96.6 \%$ ), M. incognita (96.1 to $96.3 \%$ ), $M$. arenaria (95.9 to $96.3 \%)$, and $M$. paranaensis (95.8 to $96.0 \%$ ). Similarity levels of M. hispanica toward other Meloidogyne spp. were below 94\%. The MP tree supported the separation of $M$. hispanica from $M$. arenaria and $M$. incognita; the three $M$. hispanica isolates formed a single and highly supported clade with maximum bootstrap support, which was a sister clade of another formed by $M$. arenaria, $M$. paranaensis, $M$. incognita, and $M$. konaensis (Fig. 5).

Amplification of the partial $18 \mathrm{~S}$ with primers MelF/MelR yielded a single fragment of approximately $950 \mathrm{bp}$ for $M$. hispanica. Interestingly, the $18 \mathrm{~S}$ partial sequences of $M$. hispanica isolates shared $100 \%$ homology among them and with that of $M$. ethiopica present in the database. The closest sequence-related neighbors of $M$. hispanica isolates were $M$. arenaria, $M$. floridensis, $M$. incognita, and $M$. javanica
(99.7\%) that showed difference on only two nucleotides. Similarity levels of $M$. hispanica toward other Meloidogyne spp. were 99.6 to $97.5 \%$. The optimal phylogenetic tree obtained from MP analysis showed that the $M$. hispanica isolates and $M$. ethiopica formed an independent clade with a high bootstrap support (87\%) that was a sister clade of another, including $M$. arenaria, $M$. floridensis, $M$. incognita, and M. javanica that also shared $100 \%$ homology among themselves (Fig. 6).
The substantial sequence divergence (4.1 to $61.4 \%)$ in the ITS1-5.8S-ITS2 and (4.5 to $25.9 \%$ ) in the D2-D3 region fragment and the low (0.3 to $3.1 \%)$ although consistent sequence divergence in the $18 \mathrm{~S}$ for the $M$. hispanica species distinguish it from other studied Meloidogyne spp. and support its separate specific status.

\section{DISCUSSION}

The accurate biological identification and pathogenic characterization of root-

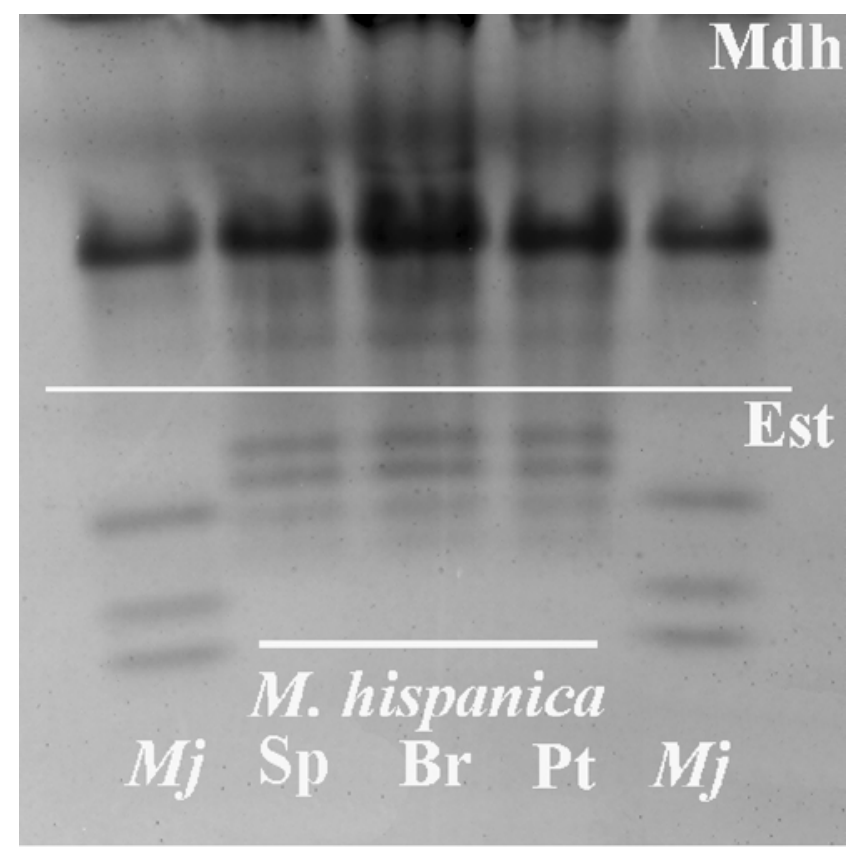

Fig. 2. Esterase (Est) and malate dehydrogenase (Mdh) electrophoresis patterns of protein homogenates from five young, egg-laying females of Meloidogyne hispanica isolates from Spain (Sp), Brazil $(\mathrm{Br})$, and Portugal $(\mathrm{Pt}) ;$ M. javanica $(M j)=$ reference isolate.
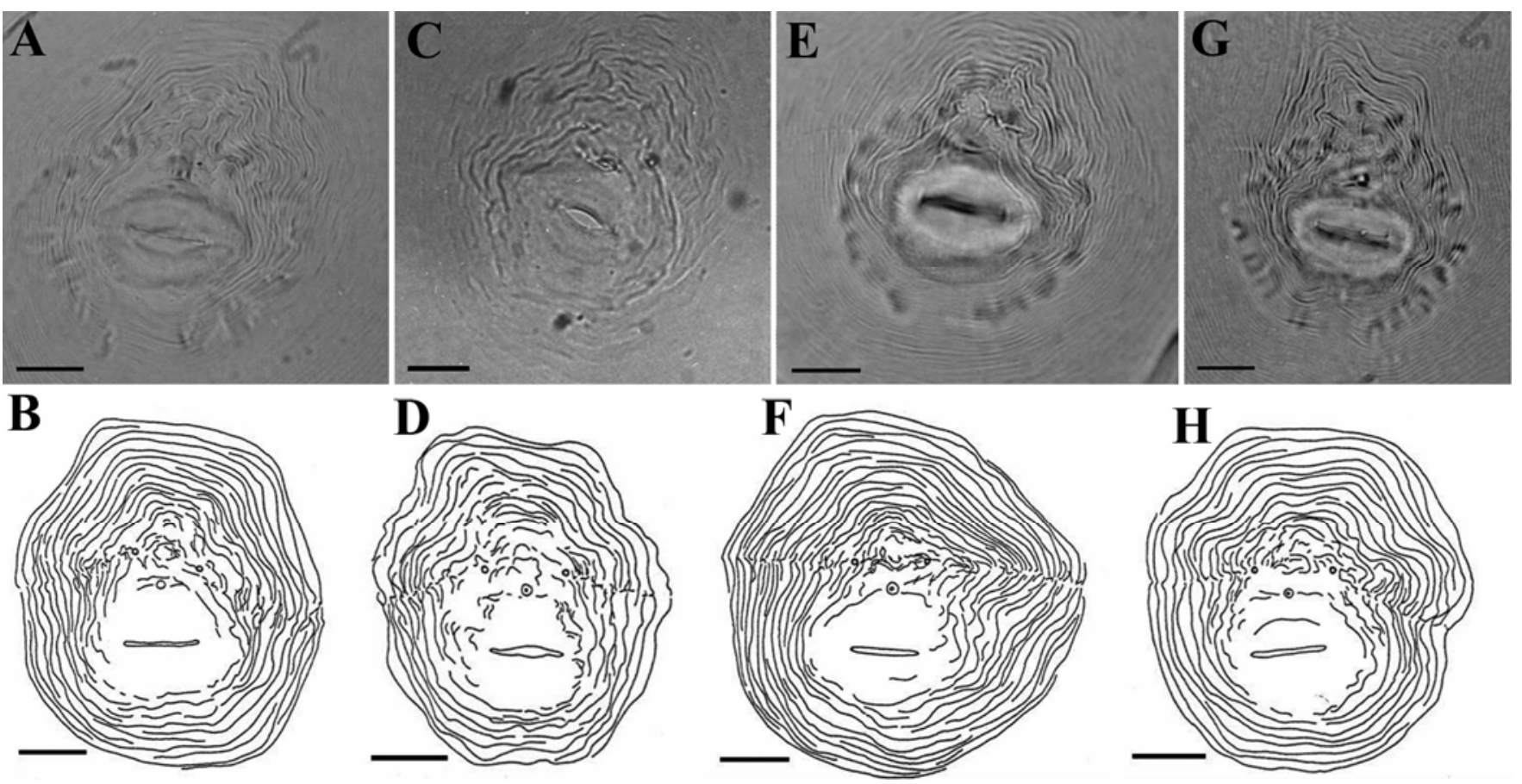

Fig. 1. Variability of perineal patterns of Meloidogyne hispanica isolates from $\mathbf{A}$ and $\mathbf{B}$, Brazil; $\mathbf{C}$ and $\mathbf{D}$, Portugal; and $\mathbf{E}-\mathbf{H}$, Spain. Upper part: photomicrographs. Lower part: line drawings. Scale bars: $20 \mu \mathrm{m}$. 
knot nematodes infecting a crop is a prerequisite for designing effective control strategies. This is particularly relevant for $M$. hispanica, which can be very difficult

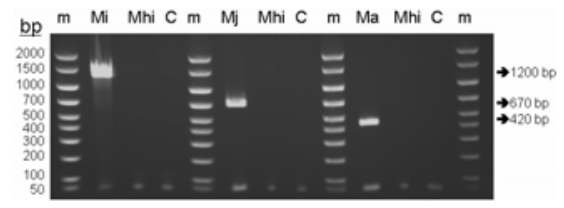

Fig. 3. Representative polymerase chain reaction amplification products using primer pairs Finc/Rinc, Fjav/Rjav, and Far/Rar and 1 to $10 \mathrm{ng}$ of template DNA of Meloidogyne hispanica (Mhi) isolate from Seville, Spain; M. incognita (Mi), M. javanica (Mj), and M. arenaria (Ma) reference isolates; and control (C). Similar results were obtained with Mhi isolates from Portugal and Brazil. to distinguish from the mitotically parthenogenetic root-knot nematodes $M$. arenaria and $M$. incognita. The biochemical electrophoretic analysis of isozyme electrophoretic patterns, in particular Est and Mdh phenotypes, are rapid and efficient methods of identification for rootknot nematodes and have been proved to be a valuable tool for identification of Meloidogyne spp. $(16,21)$. The results of Est phenotypes of the three isolates of $M$. hispanica were similar among them and agree with previous results $(10,18,28)$. However, our results with the Mdh phenotypes, showing an N3 phenotype, were coincident with previous studies $(10,28)$ but clearly different from those by Esbenshade and Triantaphyllou (18), who reported an N1 phenotype in four populations from Fiji, Korea, Portugal, and Spain.
These controversial results with Mdh phenotypes may be related to the differential time used for staining in each study. In this study, the presence of two additional, weaker bands was observed only after prolonged staining.

The rDNA unit is particularly appropriate for phylogenetic analyses because it includes highly conserved regions as well as highly variable regions and has been extensively used to reconstruct phylogenetic relationships among organisms with varying degrees of relatedness (22). Phylogenetic studies within Meloidogyne spp. have demonstrated that D2 and D3 expansion regions of the $28 \mathrm{~S}$ rRNA gene may provide initial insight toward resolving phylogenetic relationships among Meloidogyne spp. which remain unresolved when using ITS regions (13). Those re-

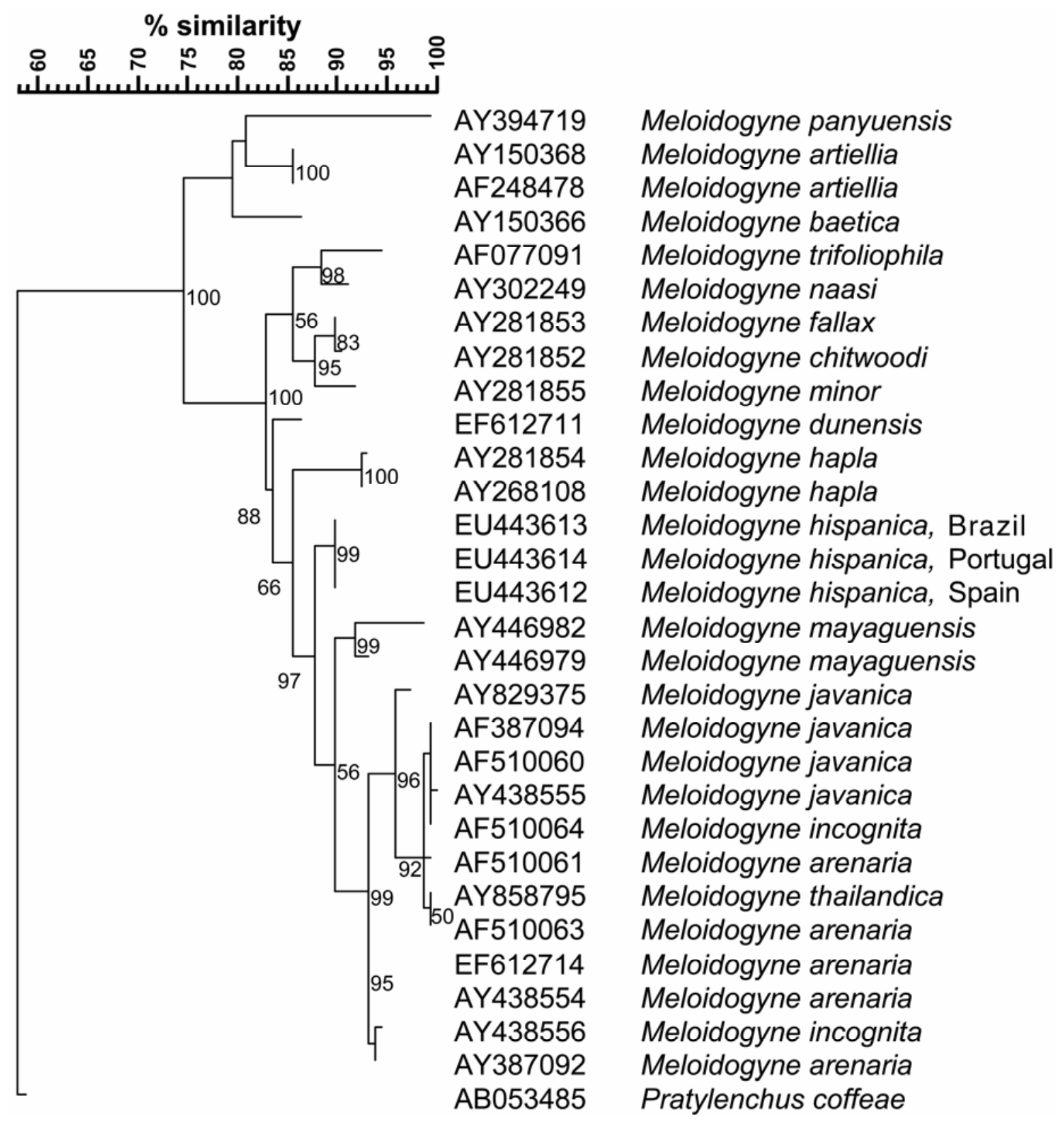

Fig. 4. Rooted maximum parsimony tree resulting from analysis of alignments of internal transcribed spacer (ITS)1-5.8S-ITS2 ribosomal DNA sequences of Meloidogyne hispanica with other root-knot nematodes. Bootstrap support more than $50 \%$ given for appropriate clade. 


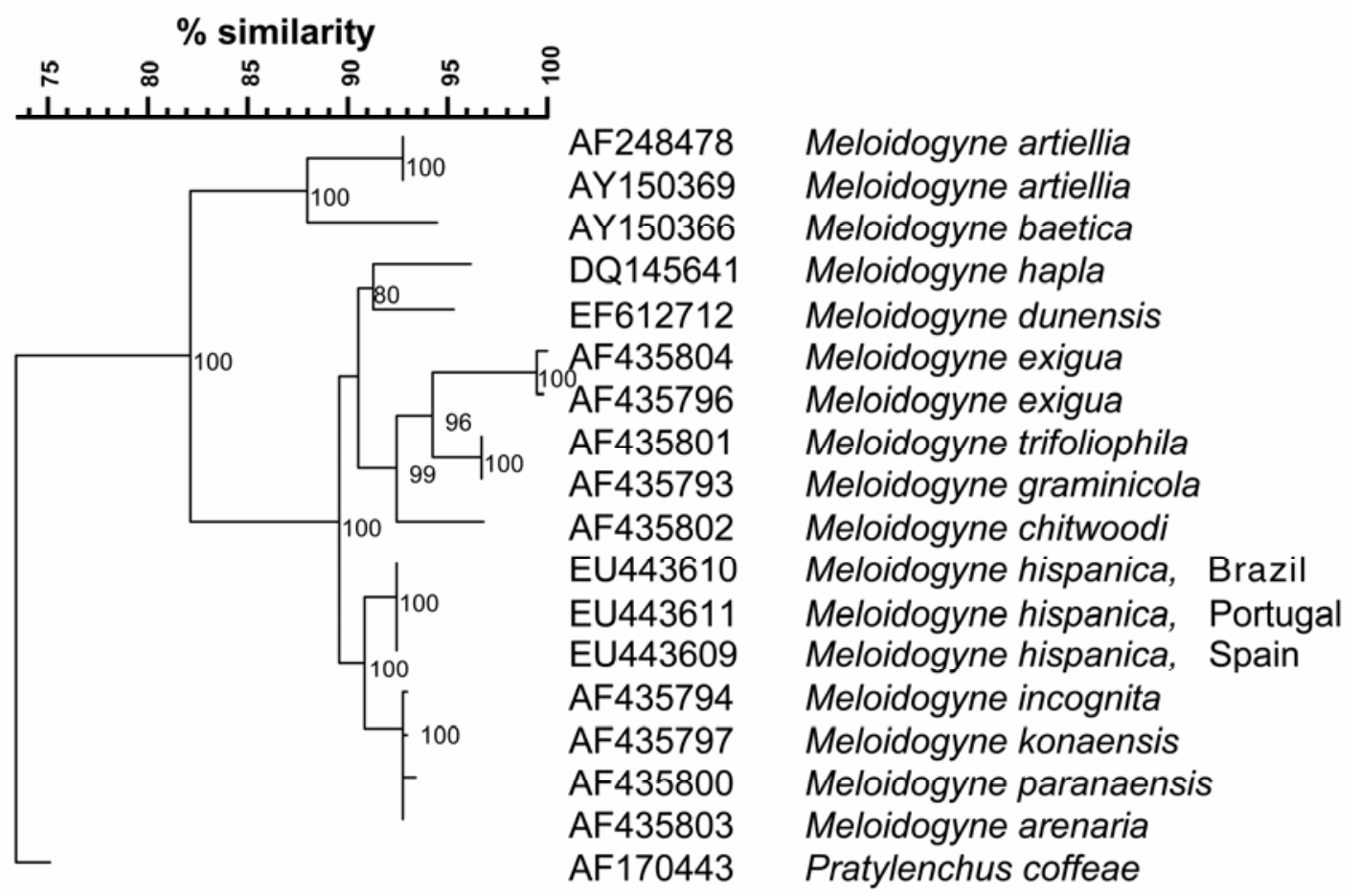

Fig. 5. Rooted maximum parsimony tree resulting from analysis of alignments of $18 \mathrm{~S}$ sequences of Meloidogyne hispanica with other root-knot nematodes. Bootstrap support more than $50 \%$ given for appropriate clade.

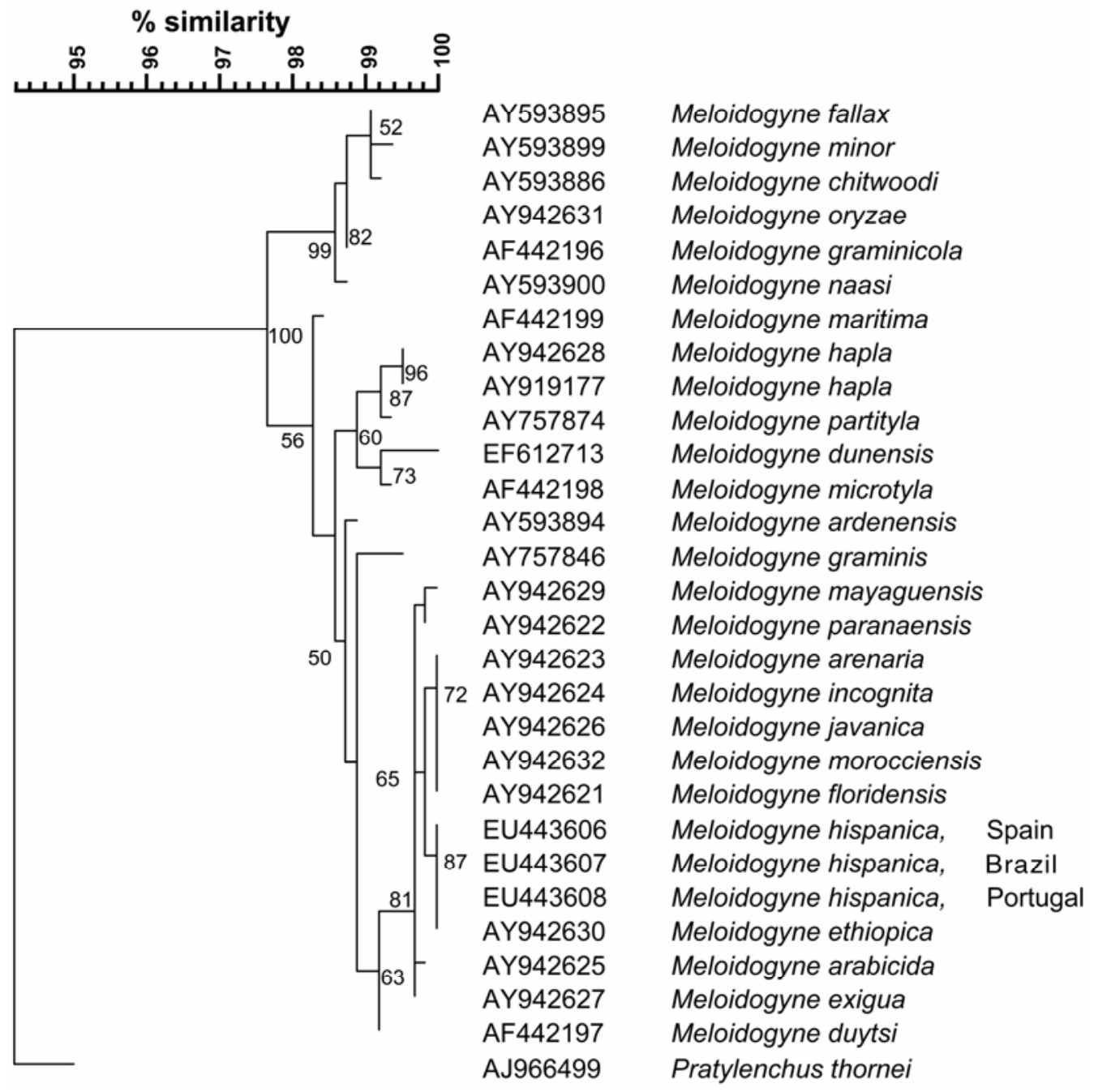

Fig. 6. Rooted maximum parsimony tree resulting from analysis of alignments of sequences of D2-D3 region of 28S of ribosomal DNA of Meloidogyne hispanica with other root-knot nematodes. Bootstrap support more than $50 \%$ given for appropriate clade. 
gions have exhibited sufficient variability to allow estimation of the historical relationships among Meloidogyne spp. $(7,29,33,34)$. The MP analysis provided phylogenetic relationship among different Meloidogyne spp. similar to those reported before, identifying the same main clades, especially for $18 \mathrm{~S}$ sequences $(12,29,34)$. The differences in position of some taxa and their phylogenetic relationships found in our study with that of Palomares Rius et al. (29) that included a shorted data set occurred mainly in some poorly supported clades (e.g., M. dunensis and $M$. hapla using the D2-D3 sequences and $M$. maritima and $M$. ardenensis using $18 \mathrm{~S}$ sequences). These differences also may be due to the different tree construction methods used in both studies clustering algorithms in UPGMA and NJ (29) versus optimality criterion in MP (this study). The inclusion of new taxa also may have accounted for the differences found.

In our study, in the MP analysis of the $18 \mathrm{~S}$ gene, $M$. hispanica was included in clade I as described by De Ley et al. (12) and Tigano et al. (34) with the mitotic parthenogenetic species, namely, $M$. arabicida, $M$. arenaria, $M$. incognita, $M$. javanica, M. mayaguensis, $M$. morocciensis, M. paranaensis, and M. ethiopica. Interestingly, in our study, $M$. hispanica shared identical $18 \mathrm{~S}$ partial sequence with an isolate of M. ethiopica from Brazil. An isolate of $M$. ethiopica from Chile has shown to have identical $18 \mathrm{~S}$ rDNA sequence with $M$. hispanica, but both species can be clearly differentiated by the D2-D3 sequences (P. Castillo, B. B. Landa, and N. Vovlas, unpublished results, available upon request).

Some authors have reported differences within rDNA sequences among isolates belonging to the same species, implying that some Meloidogyne spp. are more molecularly heterogeneous than previously thought $(12,34)$. In this work, we found that all three $M$. hispanica isolates from different geographical origins shared identical sequences. MP analysis from three rDNA regions (18S, ITS1-5.8S-ITS2, and D2-D3 of 28S rDNA) and the species-specific PCR demonstrated that M. hispanica can be differentiated from all described root-knot nematode species. Thus, the inclusion of these isolates in separate clades provided strong support that this nematode species is clearly separated from other species with resemblance in morphology or ecological habits, such as $M$. arenaria and $M$. incognita for which it can be regularly confused, based solely on morphological or biological traits. These molecular approaches may provide new insights to confirm nematode diagnosis made in the past and help to understand the biogeography and importance of this root-knot nematode species in agriculture.
ACKNOWLEDGMENTS

We thank D. Esmenjaud for providing the isolate of $M$. hispanica and J. Martin Barbarroja (IASCSIC) for technical assistance.

\section{LITERATURE CITED}

1. Abrantes, I. M. O., Rodrigues, A. C. F., and Santos, M. N. S. A. 1994. Identification of root-knot nematodes by isozyme analysis. Turk. Phytopathol. Soc. Publ. 7:17-18

2. Blok, V. C. 2005. Achievements in and future prospects for molecular diagnostics of plantparasitic nematodes. Can. J. Plant Pathol. 27:176-185.

3. Blok, V. C., Phillips, M. S., and Fargette, M. 1997. Comparison of sequences from the ribosomal DNA intergenic region of Meloidogyne mayaguensis and other major tropical rootknot nematodes. J. Nematol. 29:16-22.

4. Blok, V. C., Wishart, J., Fargette, M., Berthier, K., and Phillips, M. S. 2002. Mitochondrial DNA differences distinguishing Meloidogyne mayaguensis from the major species of tropical root-knot nematodes. Nematology 4:773781.

5. Carneiro, R. M. D. G., Almeida, M. R. A., and Gomes, A. C. M. M. 2004. First record of Meloidogyne hispanica Hirschmann, 1986 on squash in State of Bahia, Brazil. Nematol. Brasil. 28:215-218.

6. Castillo, P., Di Vito, M., Vovlas, N., and Jiménez-Díaz, R. M. 2001. Host-parasite relationships in root-knot disease of white mulberry. Plant Dis. 85:277-281.

7. Castillo, P., Vovlas, N., Subbotin, S., and Troccoli, A. 2003. A new root-knot nematode, Meloidogyne baetica $\mathrm{n}$. sp. (Nematoda: Heteroderidae), parasitizing wild olive in southern Spain. Phytopathology 93:1093-1102.

8. Cenis, J. L., Opperman, C. H., and Triantaphyllou, A. C. 1992. Cytogenetic, enzymatic, and restriction fragment length polymorphism variation of Meloidogyne spp. from Spain. Phytopathology 82:527-531.

9. Chen, P., Roberts, P. A., Metcalf, A. E., and Hyman, B. C. 2003. Nucleotide substitution patterning within the Meloidogyne rDNA D3 region and its evolutionary implications. J. Nematol. 35:404-410.

10. Cofcewicz, E. T., Carneiro, M.D.G., Randig, O., Chabrier, C., and Quénéherve, P. 2005. Diversity of Meloidogyne spp. on Musa in Martinique, Guadeloupe, and French Guiana. J. Nematol. 37:313-322.

11. Dalmasso, A., and Bergé, J. B. 1978. Molecular polymorphism and phylogenetic relationship in some Meloidogyne spp.: application to the taxonomy of Meloidogyne. J. Nematol. 10:323-332.

12. De Ley, I. T., De Ley, P., Vierstraete, A., Karssen, G., Moens, M., and Vanfleteren, J. 2002. Phylogenetic analyses of Meloidogyne small subunit rDNA. J. Nematol. 34:319-327.

13. De Ley, I. T., Karssen, G., De Ley, P., Vierstraete, A., Waeyenberge, L., Moens, M., and Vanfleteren, J. 1999. Phylogenetic analyses of internal transcribed spacer region sequences within Meloidogyne. (Abstr.) J. Nematol. 31:530-531.

14. Di Vito, M., Battistini, A., and Catalano, L. 2002. Response of Prunus rootstocks to rootknot (Meloidogyne spp.) and root-lesion (Pratylenchus vulnus) nematodes. Acta Hortic. 592:663-668.

15. Duncan, L. W., Inserra, R., Thomas, W. K., Dunn, D., Mustika, I., Frisse, L. M., Mendes, M. L., Morris, K., and Kaplan, D. T. 1999. Molecular and morphological analysis of isolates of Pratylenchus coffeae and closely related species. Nematropica 29:61-80.

16. Eisenback, J. D., and Triantaphyllou, H. H. 1991. Root-knot nematodes: Meloidogyne species and races. Pages 191-274 in: Manual of Agricultural Nematology. W. R. Nickle, ed.
Marcel Dekker, Inc., New York.

17. Esbenshade, P. R., and Triantaphyllou, A. C. 1985. Electrophoretic methods for the study of root-knot nematode enzymes. Pages 115-123 in: An Advanced Treatise on Meloidogyne, Vol. II. Methodology. K. R. Barker, C. C. Carter, and J. N. Sasser, eds. North Carolina State University Graphics, Raleigh.

18. Esbenshade, P. R., and Triantaphyllou, A. C. 1985. Use of enzyme phenotypes for identification of Meloidogyne species. J. Nematol. 17:6-20.

19. Esmenjaud, D., Minot, J. C., Voisin, R., Pinochet, J., Simard, M. H. J., and Salesses, G. 1997. Differential response to root-knot nematodes in Prunus species and correlative genetic implications. J. Nematol. 29:370-380.

20. Fargette, M. 1987. Use of the esterase phenotype in the taxonomy of the genus Meloidogyne. 2. Esterase phenotypes observed in West African populations and their characterization. Rev. Nématol. 10:45-56.

21. Flores-Romero, P., and Navas, A. 2005. Enhancing taxonomic resolution: distribution dependent genetic diversity in populations of Meloidogyne. Nematology 7:517-530.

22. Hillis, D. M., and Dixon, M. T. 1991. Ribosomal DNA: Molecular evolution and phylogenetic inference. Q. Rev. Biol. 66:411-435.

23. Hirschmann, H. 1986. Meloidogyne hispanica n. sp. (Nematoda: Meloidogynidae), the 'Seville root-knot nematode.' J. Nematol. 18:520-532.

24. Hugall, A., Moritz, C., Stanton, J., and Wolstenholmes, D. R. 1994. Low, but strongly structured mitochondrial DNA diversity in root knot nematodes (Meloidogyne). Genetics 136:903-912.

25. Karssen, G., and Van Hoenselaar, T. 1998 Revision of the genus Meloidogyne Goldi, 1982 (Nematoda: Heteroderidae) in Europe. Nematologica 44:713-788.

26. Kleynhans, K. P. N. 1993. Meloidogyne hispanica Hirchmann, 1986 and M. ethiopica Whitehead, 1968 in South Africa (Nemata: Heteroderidae). Phytophylactica 25:283288.

27. Nico, A. I., Rapoport, H. F., Jiménez-Díaz, R M., and Castillo, P. 2002. Incidence and population density of plant-parasitic nematodes associated with olive planting stocks at nurseries in southern Spain. Plant Dis. 86:1075-1079.

28. Pais, C. S., and Abrantes, I. M. O. 1989. Esterase and malate dehydrogenase phenotypes in Portuguese populations of Meloidogyne species. J. Nematol. 21:342-346.

29. Palomares Rius, J. E., Vovlas, N., Troccoli, A., Liébanas, G., Landa, B. B., and Castillo, P. 2007. A new root-knot nematode parasitizing sea rocket from Spanish Mediterranean coastal dunes: Meloidogyne dunensis n. sp. (Nematoda: Meloidogynidae). J. Nematol. 39:190-192.

30. Pinochet, J., Anglés, M., Dalmau, E., Fernández, C., and Felipe, A. 1996. Prunus rootstock evaluation to root-knot and lesion nematodes in Spain. J. Nematol. 28:616-623.

31. Stanton, J., Hugall, A., and Moritz, C. 1997. Nucleotide polymorphisms and an improved PCR-based mtDNA diagnostic for parthenogenetic root-knot nematodes (Meloidogyne spp.). Fundam. Appl. Nematol. 20:261-268.

32. Taylor, D. P., and Netscher, C. 1974. An improved technique for preparing perineal patterns of Meloidogyne spp. Nematologica 20:268-269.

33. Tenente, G. C. M. V., De Ley, P., Tandingan De Ley, I., Karssen, G., and Vanfleteren, J. R. 2004. Sequence analysis of the D2/D3 region of the large subunit rDNA from different Meloidogyne isolates. Nematropica 34:1-12.

34. Tigano, M. S., Carneiro, R., Jejaprakash, A., Dickson, D. W., and Adams, B. 2005. Phylogeny of Meloidogyne spp. based on 18 S rDNA 
and mitochondrial sequences. Nematology 7:851-862.

35. Triantaphyllou, A. C. 1985. Cytogenetics, cytotaxonomy and phylogeny of root-knot nematodes. Pages 113-126 in: An Advanced Treatise on Meloidogyne, Vol. I. Biology and Control. J. N. Sasser and C. C. Carter, eds., North Carolina State University Graphics, Raleigh.

36. Trudgill, D. L., Bala, G., Blok, V. C., Daudi, A., Davies, K. G., Gowen, S. R., Fargette, M.,
Madulu, J. D., Mateille, T., Mwageni, W., Netscher, C., Philips, M. S., Sawadogo, A., Trivino, C. G., and Voyoukallou, E. 2000. The importance of tropical root-knot nematodes (Meloidogyne spp.) and factors affecting the utility of Pasteuria penetrans as a biocontrol agent. Nematology 2:823-845.

37. Vovlas, N., Midsuf, D., Landa, B. B., and Castillo, P. 2005. Pathogenicity of the rootknot nematode Meloidogyne javanica on potato. Plant Pathol. 54:657-664.
38. Wishart, J., Phillips, M. S., and Blok, V. C. 2002. Ribosomal intergenic spacer: A polymerase chain reaction diagnostic for Meloidogyne chitwoodi, M. fallax, and M. hapla. Phytopathology 92:884-892.

39. Zijlstra, C., Donkers-Venne, D. T. H. M., and Fargette, M. 2000. Identification of Meloidogyne incognita, $M$. javanica and $M$. arenaria using sequence characterised amplified region (SCAR) based PCR assays. Nematology 2:847-853. 